\title{
O COMÉRCIO INTERNACIONAL DE SERVIÇOS NA AMÉRICA LATINA: A DINÂMICA DE EVOLUÇÃO NOS PERÍODOS DAS RECENTES CRISES
}

\author{
INTERNATIONAL TRADE IN SERVICES IN LATIN AMERICA: \\ THE DYNAMICS OF EVOLUTION IN THE PERIODS OF THE \\ RECENT CRISES
}

\author{
Anita Kon ${ }^{(*)}$ \\ Pontifícia Universidade Católica de São Paulo, São Paulo (SP), Brasil
}

\begin{abstract}
Resumo: O artigo examina aspectos teóricos e empíricos sobre a situação do comércio internacional de serviços da América Latina, identificando as características da evolução e distribuição destes fluxos, particularmente diante das conjunturas econômicas de crises internacionais que se sucederam em períodos recentes. Inicialmente é examinado teoricamente o desenvolvimento da internacionalização de serviços, e as transformações estruturais consideráveis, resultantes dos impactos do processo de globalização e seus reflexos na evolução fluxos internacionais dos serviços. Finalmente, são analisadas empiricamente a distribuição e evolução dos serviços da América Latina no contexto do comércio mundial, verificando as tendências de desenvolvimento de países selecionados.
\end{abstract}

Palavras-chave: Comércio de serviços; Crises econômicas internacionais; Globalização.

\begin{abstract}
The article examines theoretical and empirical aspects of the international trade in services situation in Latin America, identifying the characteristics of the evolution and distribution of these flows, particularly given the economic situations of the international crises that followed in recent periods. Initially it is theoretically analyzed the internationalization development of services activities and the considerable structural transformations resulting from the impacts of globalization and also its effects on international flows. Finally, it is empirically analyzed the distribution and evolution of services in Latin America in the context of world trade by checking the development trends of selected countries.
\end{abstract}

Keywords: Trade in services; International economic crises; Globalization.

${ }^{*}$ ) Doutora, Professora do Departamento de Ciências Econômicas da Pontifícia Universidade Católica de São Paulo; Coordenadora do Grupo de Pesquisas em Economia Industrial, Trabalho e Tecnologia do Programa de Estudos Pós-graduados em Economia Política (PEPGEP — PUC/SP); Consultora do Instituto de Economia Política Aplicada (IPEA); Assessora econômica da Universidad Autónoma de Madrid. E-mail: <anitakon@pucsp.br>. Recebido em: 04.10.2013, aceito em: 27.12.2013. 


\section{INTRODUÇÃO}

O relevante desenvolvimento da produção econômica internacional no final da década de 1990, que teve continuidade no início dos anos 2000, foi acompanhado pela expansão considerável dos fluxos de comércio internacional. Neste período, além de enfrentar questões relacionadas à busca da estabilização macroeconômica, grande parte dos países da América Latina se mobilizaram para participarem mais ativamente da competição neste mercado mundial, seja elevando seus esforços para exportação, seja para a importação de insumos necessários para a modernização e ampliação da capacidade produtiva.

Neste contexto, observa-se o papel relevante dos setores produtivos de serviços como indutor do aumento da produtividade das empresas e do desenvolvimento econômico, pelos seus impactos sistêmicos marcantes, tanto em nível micro quanto macroeconômico, resultantes da introdução da inovação em serviços nos processos produtivos e na organização, com a criação de novas modalidades de serviços ou ampliação das possibilidades de comercialização internacional destas atividades. A capacidade de cada economia de elevar os movimentos de suas vendas e compras internacionais de serviços específicos resulta, portanto, na possibilidade de aumentar sua competitividade interna e internacional. Por outro lado, a ampliação destes fluxos internacionais nos diferentes países recebe impactos consideráveis de fatores geográficos relacionados à sua localização territorial em relação aos principais mercados, dos recursos financeiros e materiais, da concentração de conhecimento e de capacidades dos agentes produtivos.

Este artigo examina alguns aspectos teóricos e empíricos sobre a participação e a possibilidade de evolução da América Latina no comércio internacional de serviços, onde são evidentes algumas destas desvantagens geográficas e econômicas, particularmente diante de conjunturas econômicas de crises internacionais que se sucederam no período. Em primeiro lugar é examinado teoricamente o desenvolvimento da internacionalização de serviços, e as transformações estruturais consideráveis, resultantes dos impactos do processo de globalização e seus reflexos na evolução fluxos internacionais dos serviços. Finalmente são analisadas empiricamente a distribuição e evolução dos serviços da América Latina no contexto do comércio mundial, particularmente nos períodos recentes de crise internacional.

\section{O DESENVOLVIMENTO DA INTERNACIONALIZAÇÃO DE SERVIÇOS}

Com os avanços tecnológicos nas áreas de transportes e comunicações do pós-guerra, o aparato produtivo das empresas é deslocado para o exterior, inicialmente, com a internacionalização da produção de produtos acabados. Posteriormente, a partir do final dos anos 1960 (particularmente com o avanço da microeletrônica e da tecnologia da informação), em alguns setores, o processo de produção é internacionalizado, como desenvolvimento de cada parte do processo em uma diferente região mundial. O fenômeno da globalização, intensificado no mercado mundial na década de 1990, é, portanto, um processo histórico de internacionalização do capital, que se difundiu com maior velocidade, especialmente, a partir das três últimas décadas, graças ao avanço tec- 
nológico. Neste contexto, desde a década de 1980, configurou-se uma nova etapa mais avançada e veloz de transformações tecnológicas e de acumulação financeira, intensificando a internacionalização da vida econômica, social, cultural e política.

Os resultados dessa dinâmica, observados na atualidade, mostram que o papel desempenhado pelos setores de serviços no desenvolvimento econômico é fundamental em qualquer nível do processo de desenvolvimento dos países. Enquanto estes setores apresentam características diferentes nas economias desenvolvidas ou em desenvolvimento, estas atividades permanecem na atualidade como sua fonte mais relevante de empregos. No entanto, este papel é estendido para muito além da prestação de serviços a outros setores, uma vez que é provado o caráter independente e indutivo ao desenvolvimento incorporado em algumas das atividades dinâmicas de serviços (KON, 2004). O crescimento e a modernização desses setores em uma economia é um requisito fundamental para este desenvolvimento e não simplesmente um coadjuvante no seu resultado final ou no produto e o desempenho do setor de serviços são vitais para a redução da pobreza.

O desempenho dos serviços é importante para as economias modernas. Para citar só um exemplo, o crescimento do comércio internacional dos serviços vem colaborando para a entrada de rendimentos e poupança, por meio das vendas para exterior. Portanto, o aprovisionamento das atividades de serviços é um elemento crucial na dinâmica do processo de desenvolvimento de qualquer país (KON, 2004).

No tocante ao comércio exterior de serviços, são encontrados nas análises alguns conceitos tradicionais sobre o caráter não comercializável internacionalmente destas atividades (BAUMOL, 1987; BRYSON e WHITE, 1997; KON, 2004; REINHARDT, 2011 ). Mesmo em análises mais recentes ainda existem trabalhos que adotam estas premissas tradicionais ao enfatizar a falta de cooperação para a formação de poupança nacional causada pela característica de serem produtos non tradable e, dessa forma, não gerarem absorção de poupança externa: segundo Samuel Pessoa (apud DANTAS, 2012): "dado que os serviços são não comercializáveis internacionalmente, a absorção de poupança externa pode ocorrer na forma de bens manufaturados e de bens primários."

Por outro lado, esta característica do conceito tradicional é também considerada como relevante para a elevação da inflação e dificulta o desenvolvimento da indústria das economias menos desenvolvidas, desde que a poupança interna será investida em importação de manufaturados: "A tragédia para a indústria é a assimetria entre os serviços e os bens manufaturados. Estes últimos são transacionados internacionalmente, ao contrário dos serviços." (apud DANTAS, 2012.) A ideia presente nestas análises tradicionais é de que, em países em desenvolvimento com altas taxas de consumo e baixas taxas de poupança, a demanda é mais concentrada em serviços do que em bens. Nessa situação, que é mais verdadeira em sociedades em que o padrão de consumo é muito concentrado em serviços e se aproxima do nível da classe média, a não possibilidade de importação de serviços aumenta os seus preços internos anteriormente à elevação da oferta. $\mathrm{O}$ mesmo não ocorre com os bens primários ou manufatureiros, que podem atender sua demanda interna pela importação.

Nas análises mais recentes neo-schumpeterianas, a ideia da relevância dos serviços como também indutoras no contexto do desenvolvimento econômico, não deve ser in- 
terpretada em termos comparativos ou substitutivos entre estas atividades e as demais como em um jogo de perdas e ganhos, mas sim como elementos conjuntamente influentes no processo. As atividades de serviços são cogeradoras de produtividade e de valor adicionado em todos os setores produtivos. Além do mais, embora seja patente a baixa participação relativa do comércio exterior de serviços quando comparada à das mercadorias, observa-se em termos absolutos um montante considerável no valor monetário dos fluxos transacionados (KON, 2012).

O comércio exterior de serviços é um elemento importante, na pauta da maioria dos países, nesta fase de globalização econômica. Os fluxos de comércio externo de serviços observados levam à reformulação da ideia anterior sobre a natureza intrínseca de non-tradable internacionalmente de toda a ampla gama destas atividades, para dar lugar à verificação da relevância dos serviços específicos comercializados no exterior. Já o crescimento dos serviços "Tradable" é fato constatado e mensurável.

As transações internacionais de serviços, no entanto, muitas vezes, continuam a ser impedidas ou dificultadas por barreiras políticas e econômicas. Os países em desenvolvimento teriam muito a se beneficiar pela maior liberalização destas atividades. A partir do reconhecimento da relevância dos fluxos de serviços no comércio internacional, bem como a necessidade de maior liberalização, estas atividades foram incluídas como relevantes na arquitetura dos tratados de comércio multilateral conforme formatado pelo Acordo Geral de Comércio Exterior em Serviços (General Agreementon Trade in Services — GATS), elaborado pela OMC.

O desenvolvimento relevante da produção econômica mundial no século $\mathrm{XX}$, que continuou a aumentar até o período recente que antecedeu a crise financeira internacional de 2008, foi acompanhado pela considerável expansão dos fluxos de comércio internacional de mercadorias e serviços. Neste contexto, a produção econômica mundial é consideravelmente afetada por fatores geográficos, desde que a localização geográfica dos recursos financeiros e materiais, recursos de conhecimento e produção, juntamente com a proximidade ou afastamento dos principais mercados, conduzem as estratégias econômicas e táticas dos países no cenário de comercialização mundial. Outros aspectos relevantes internos aos países interferem nos resultados como a natureza da especialização internacional, formas de agrupamentos industriais, relações entre comércio externo e geografia interna, evolução e diferenças tarifárias, bem como os diferentes instrumentos do comércio legal dos países, entre outros. A geoeconomia é frequentemente associada à geopolítica, no que se refere aos princípios básicos da teoria das relações internacionais, que define o papel e as formas históricas específicas e que influenciam as diferentes situações ou barreiras internacionais dos processos regionais, continentais ou globais (KON, 2012).

\section{AS TRANSFORMAÇÕES ESTRUTURAIS: IMPACTOS DO PROCESSO DE GLOBALIZAÇÃO NA EVOLUÇÃO DOS SERVIÇOS}

Na segunda metade do século XX, a concentração crescente de excedentes de capital, que eram então exportados, levou a um novo estágio de desenvolvimento indus- 
trial, mediante investimentos diretos vindos de grandes empresas estrangeiras, para a produção de matérias-primas e produtos fabricados, em sua busca de mercados maiores, fatores de produção menos onerosos e de maior retorno sobre o capital investido. As transformações na estrutura produtiva que então ocorreram não se deram apenas no montante de produto gerado ou nos processos tecnológicos.

Como apontado por Hauknes (1996), quando as tecnologias inovadoras, especialmente na área de informação, são aplicados aos serviços, elas mudam sua estrutura interna e global competitiva, tanto nas indústrias de bens quanto de serviços, e cresce a participação dos serviços em indústrias transformadoras. Assim, novas economias de escala aparecem em grandes instituições que muitas vezes têm uma estrutura produtiva doméstica ou internacional descentralizada. Por outro lado, as novas economias de escopo criadas por tais tecnologias apresentam constantemente efeitos secundários inesperados, ou seja, benefícios ou externalidades positivas. Além do mais, a complexidade econômica e a ampliação constante da população mundial requer mecanismos mais eficazes para serem conduzidos, pelas novas tecnologias imateriais que proporcionam uma melhor organização e difusão do consumo ou, ainda, a implementação de processos e de relações entre agentes, anteriormente impossíveis.

Em anos mais recentes, particularmente depois da década de 1990, a economia mundial se caracterizou por mudanças substanciais mais intensas na natureza da produção e as demandas por bens e serviços começaram a ser atendidas por uma economia mundial. Tal década foi palco da aceleração da globalização das atividades econômicas, com a proliferação das empresas transnacionais. O processo de maior integração desenvolveu os serviços de transportes e serviços mais sofisticados, como a construção civil, o planejamento, também passaram a se desenvolver. Dessa forma, grupos sofisticados de serviços estão substituindo as atividades manufatureiras tradicionais enquanto setores líderes de economias avançadas e possivelmente das economias em desenvolvimento.

A desregulação dos serviços financeiros e o advento de modos avançados de comunicação intensificaram a internacionalização de firmas de serviços financeiros. A globalização da economia mundial criou um novo papel para as cidades que são eixos internacionais de negócios. Originalmente, as atividades bancárias internacionais se desenvolveram como um complemento do comércio internacional, pois é um imperativo das instituições financeiras ter a presença física próxima do cliente e uma presença ativa nos mercados mais relevantes, a fim de realizar os negócios que são intensificados por conexões diretas confiáveis. Apenas recentemente as atividades bancárias internacionais e o comércio internacional se colocam separadamente como duas partes de uma rede mundial ao invés de formarem uma unidade. Apoiados pela base financeira, outras atividades de serviços vêm se difundindo mundialmente, visando ao atendimento de assessoria a empresas ou à demanda de serviços de consumo familiar.

No caso da América Latina, além da importação de serviços financeiros e de telecomunicações, uma série de empresas prestadoras de serviços, de outras nacionalidades, vêm investindo no mercado destes países, mais intensamente desde o segundo quinquênio dos anos noventa, principalmente por meio de franquias. Trata-se particularmente de serviços de limpeza doméstica, oficinas mecânicas, lavanderias, locação de veículos, 
redes de fast-food, serviços hospitalares e serviços de atendimento a empresas e domicílios, entre outros. A globalização destes serviços tem provocado, a médio prazo, redução de preços do setor no mercado latino-americano, tendo em vista que, de uma forma geral, estes serviços utilizam padrões de qualidade e de eficiência (estabelecidos pela matriz) superiores às similares nacionais, resultantes da tecnologia usada ou de insumos importados para sua operacionalização, com ganhos de escala e, muitas vezes, com processos automatizados. A importação destes serviços apresenta reflexos consideráveis no comércio internacional e Balanço de Pagamento dos países (OCDE, 2008 e WORLD BANK, 2008).

Com o aumento da eficiência dos transportes e da comunicação, principalmente com o surgimento de uma Economia da Informação, as transformações produtivas e a internacionalização econômica resultaram na crescente integração dos serviços, o que explica o aumento significativo de seu consumo. (KON, 2012). (12)

O mercado internacional para serviços se ampliou consideravelmente, desde que a incerteza econômica por parte das firmas tornou necessários ajustes no seu comportamento, para conter os custos e também a competição nos mercados mais dinâmicos. A atualização da informação e do conhecimento sobre processos organizacionais e produtivos é uma busca constante e os fluxos internacionais destes insumos resultam da ampliação da concorrência globalizada. Foi o desenvolvimento dos serviços de transportes e comunicações que permitiram a instalação de novos estabelecimentos de produção em outros países e seriam base para relações sólidas de produção e distribuição internacionais (OCDE, 2008 e WORLD BANK, 2008).

O papel dos serviços como indutor do desenvolvimento pode ser explicado pelo seu impacto sistêmico nas economias de todos os países e na economia mundial que resulta da introdução de inovação tecnológica nos processos de produção e nas organizações, mediante a criação de novos serviços ou da atualização e aprimoramento dos já existentes. O progresso tecnológico sistêmico é uma nova forma de parceria, cada vez mais disseminada mundialmente, que elimina barreiras entre economias mais avançadas e são rapidamente introduzidas em serviços como finanças, comunicações, transporte e saúde, que transformam as atividades tradicionais anteriores em empresas de serviços intensivas em capital. Há uma parcela crescente de serviços no processo de produção e distribuição das atividades manufatureiras que aumenta a dependência da indústria de atividades terciárias.

Algumas economias, no entanto, sofrem outros tipos de pressão da economia globalizada e não conseguem criar estímulos diretos ao comércio exterior. Tais países acabam se esforçando por resolver problemas internos referentes à estabilização econômica ou o controle da inflação, por exemplo. Antes da crise financeira de 2008, melhorias na tecnologia da informação e comunicação, bem como a inexistência de barreiras ou barreiras fracas ao comércio e investimento internacional observado, haviam começado a incentivar o desenvolvimento de cadeias de fornecimento, a transferência de tecnologia e oportunidades de geração de emprego em mercados emergentes. No entanto, resultados mais rápidos e efetivos foram vistos em países já desenvolvidos, graças à infraestrutura material e financeira já existente (OCDE, 2008). 


\section{O COMÉRCIO EXTERIOR DE SERVIÇOS NA AMÉRICA LATINA}

\subsection{IMPACTOS DO CENÁRIO CONJUNTURAL NOS FLUXOS DE SERVIÇOS: 2000 A 2011 \\ 4.1.1 DA PRIMEIRA CRISE INTERNACIONAL DO MILÊNIO À RETOMADA DOS FLUXOS: 2000-2007}

Os rápidos avanços tecnológicos ocorridos nas últimas décadas do século XX nas áreas de computação, transportes e telecomunicações, incluindo o desenvolvimento da Internet e e-commerce, levaram empresas latino-americanas à busca de suprimentos disponíveis em espaços mais distantes, para servirem como insumos que lhes permitiria também atender aos mercados mais amplos. Esta tendência em direção à globalização foi reforçada por políticas de liberalização associadas à desregulação de atividades econômicas, que promoveu o crescimento de investimentos diretos internacionais em comércio exterior não apenas de bens, mas também de serviços.

Na segunda metade dos anos 1990, os fluxos mundiais de comércio haviam sofrido uma diminuição no contexto da dinâmica das economias, porém, as taxas de crescimento não foram desprezíveis e nova tendência de crescimento se verificou no ano de 2001, particularmente no item Transportes que superou as Viagens, particularmente Transportes de Carga. A economia mundial havia emergido da desaceleração do início dos anos 1990 e da crise financeira ocorrida em 1997-1998, apresentando em 1999 uma aceleração na taxa de crescimento do produto global.

Neste contexto, os fluxos mundiais de Serviços Comerciais tiveram, no primeiro quinquênio da década de 1990, taxas de crescimento anuais consideravelmente superiores às do período posterior da década, em todas as categorias de serviços. Particularmente os ligados a Outros Serviços auxiliares às empresas, cujo crescimento anual de $16 \%$ foi inusitado e não se repetiu até o final da década. O crescimento do consumo em Viagens neste primeiro período também foi significativo, desde que a conjuntura internacional favorecia o turismo e os negócios.

No entanto, o início de um novo processo de recessão era perceptível desde o final dos anos 2000 e começo de 2001 nos países industrializados, e os acontecimentos catastróficos dos ataques terroristas aos Estados Unidos em 11 de setembro de 2001 agudizaram a situação. Nos três primeiros trimestres de 2001, a desaceleração da economia norte-americana já mostrava seus efeitos nocivos sobre o desempenho de outros países, não apenas os menos desenvolvidos, mas também os mais avançados.

Certamente, os efeitos econômicos mais diretos dos atentados se relacionaram à destruição e interrupção de algumas atividades nos Estados Unidos, durante alguns dias, como o fechamento de escritórios, restaurantes, estabelecimentos comerciais na zona afetada, suspensão de atividades financeiras, de seguros e imobiliários, bem como do transporte aéreo. Estas perdas diretas, estimadas pelo Banco Mundial (2002) em 1,5\% da produção trimestral do país, se difundiram sobre outras atividades por efeitos diretos e indiretos e também sobre o consumo privado. Dessa forma, o choque de 11 de setembro reforçou as tendências que já eram observadas nos indicadores econômicos tanto 
daquele país quanto em âmbito mundial e postergou a recuperação da economia norte-americana em um ou dois trimestres e, como consequência, a retomada do crescimento do comércio mundial.

Os Estados Unidos, como já visto, antes exportador de crescimento e importador de bens intermediários, capital e consumo, tornou-se exportador do processo de retração e da dificuldade de sobrevivência de empresas de graus diversos de aporte de capital, difundidos inicialmente com maior rapidez por intermédio das organizações multinacionais e transnacionais. Uma gradual transformação nos relacionamentos básicos entre as instituições e os agentes sociais e econômicos é observada entre governos, entre empresas, governos e empresas, governo e cidadãos, ou entre empresas e consumidores, particularmente retraindo a internacionalização de serviços (KON, 2004).

Estes acontecimentos afetaram as economias latino-americanas de diferentes formas, sendo diverso o quadro geral de país para país. O crescimento do comércio mundial sofreu uma desaceleração de 13\% em 2001 e até fevereiro de 2002 já havia decrescido $2 \%$. Os preços das commodities, exceto petróleo, declinaram em cerca de 7\% em 2001, desestimulando a produção, bem como o decréscimo dos fluxos do mercado de capitais no final de 2001 (WORLD BANK, 2002).

São observados os reflexos desta conjuntura sobre os fluxos de Serviços Comerciais Internacionais que registraram crescimento quase nulo $(0,1 \%)$ e taxas negativas nas categorias de Transportes e Viagens. Além das medidas das instituições financeiras públicas, uma das questões mais relevantes relacionadas à mudança de atitudes das organizações privadas, depois de 11 de setembro, se relaciona à atitude em relação aos planos de investimentos. No que se refere às organizações produtivas, especialmente, às multinacionais ou transnacionais, a necessidade de conviver com esta nova realidade aumentou a incerteza com relação à política de inversões internas e dos Investimentos Diretos no Exterior (IDE). O problema de segurança colocou em xeque a continuidade do processo de abertura internacional então em curso.

De um modo geral, os países latino-americanos reagiram às repercussões dos acontecimentos, de acordo com a composição de sua estrutura produtiva, seja esta mais especializada em indústrias e serviços dinâmicos, oligopolizados e atuantes em sistemas transnacionais de produção ou comércio, seja mais tradicional e voltada para o mercado interno. De qualquer maneira, em todas as situações, o rápido fluxo interno e internacional de indivíduos, bem como de bens e serviços foi reduzido e controlado, paralelamente ao esforço de acompanhar e congelar o dinheiro usado por organizações terroristas, por meio de mudanças nas regras bancárias. As repercussões comerciais se refletiram mais fortemente no México - intensamente dependente do comércio com os Estados Unidos - mas também na América Central e no Caribe, que igualmente constituem economias estreitamente vinculadas à conjuntura dos Estados Unidos, particularmente pela especialização em exportações das indústrias maquiladoras, como as de alta tecnologia da Costa Rica e do México, mais sensíveis ao ciclo econômico.

As atividades turísticas, hoteleiras e do transporte aéreo se reduziram sensivelmente no Caribe, com o cancelamento de reservas e voos e alta dos custos resultantes das medidas de segurança e dos seguros. Entretanto, o desenvolvimento econômico foi afetado 
não apenas pelo menor dinamismo da economia norte-americana, mas também pela deterioração dos preços de exportação de seus produtos básicos. No entanto, em dezembro de 2001, os efeitos imediatos dos acontecimentos haviam se moderado, tendo em vista as medidas contracíclicas adotadas tanto por países avançados quanto da América Latina e as perspectivas de recuperação começaram a se mostrar paralelamente ao recebimento de investimentos diretos vindos do exterior (IDEs), no início de 2002 (CEPAL, 2002).

Nos países industrializados, as medidas anticíclicas de diminuição das taxas de juros do Banco Central Europeu e de outras autoridades monetárias, associadas à baixa inflação e políticas estruturais específicas, começaram a criar, também nos finais de 2001, um ambiente menos crítico para as organizações econômicas, o que propiciou o reinício da busca de melhoria na produtividade pelo aprimoramento tecnológico, com vistas à retomada do desenvolvimento, assim que a fase negativa do ciclo começasse a reversão. Começou a se delinear mundialmente uma evolução favorável no contexto geopolítico, tendo em vista a execução coordenada das políticas econômicas anticíclicas das economias industrializadas, o que facilitou a queda das taxas de juros internacionais. Os mercados financeiros recuperaram o nível de preços anteriores à crise e o preço das matérias-primas atingiu seu ponto mínimo.

Do lado das empresas, as campanhas de promoção comercial dos países industrializados da América do Norte e Europa, aliadas à melhoria do ambiente internacional, elevou as perspectivas de retomada de planos. Como consequência, os fluxos internacionais de serviços, em 2002, já apresentaram elevação considerável (6,4\%), particularmente no item de outros serviços (9\%), que representa cerca de $47 \%$ do volume total de fluxos de serviços.

\subsubsection{A CRISE INTERNACIONAL MAIS RECENTE: O PERÍODO 2008-2011}

A crise econômica e financeira que abalou a economia mundial nos últimos meses de 2008 produziu uma recessão global em 2009 que resultou no maior declínio no comércio mundial em mais de 70 anos. A taxa de crescimento deste comércio desacelerou de 6,4\% em 2007 para 2,1\% em 2008, e para uma contração de 12,2\% em 2009. A evolução histórica do valor de mercadorias e serviços no comércio exterior, tanto em países desenvolvidos como nas economias em desenvolvimento aumentou gradativa e constantemente desde os anos 1970 a 2008 (WTO, 2010).

A crise financeira de 2008, que se traduziu em uma crise econômica global, impactou fortemente a distribuição dos fluxos de comércio regional e mundial e os fluxos de comércio exterior no quarto trimestre daquele ano começaram a se deteriorar, embora de forma desigual entre as regiões. A Europa registrou o mais elevado declínio anual das suas exportações de mercadorias (-16\%), enquanto nas regiões da América do Norte e da Ásia as taxas foram, respectivamente, de 7\% e 5\%. Estimativas de 2009 apontam uma elasticidade do comércio internacional de serviços em relação ao PIB de valor até 5,0 a nível mundial, enquanto a média mundial de longo prazo dos valores anuais entre 1960 e 2008 apresenta uma elasticidade de 1,6. No entanto, para produtos manufaturados, este valor é ligeiramente superior, ou seja, respondem mais às mudanças no PIB do que os não tangíveis (MAURER e DEGAIN, 2010). 
A queda do fluxo de comércio verificada nos países desenvolvidos no ana de 2009 repercurtiu de maneir negativa no ano de 2011 (WTO, 2012), dado que, o volume destes fluxos ainda não atingiram os patamares de 2008. No entanto, as exportações de mercadorias e os fluxos de serviços já apresentaram elevação. Nos países em desenvolvimento, embora em 2011 o comércio de mercadorias tenha mostrado considerável recuperação e elevação a taxas superiores à série histórica, no que se refere aos serviços, não houve alterações em relação ao ano de 2009.

Por outro lado, a WTO (2010) mostra que, a longo prazo, a desproporção considerável de volume de comércio exterior mundial entre países desenvolvidos e em desenvolvimento permanece contínua de 1970 em diante, ainda que o crescimento também tenha se intensificado para os dois níveis. Mesmo que os dados sobre importações e exportações de bens e serviços não possam revelar algumas das características qualitativas acima mencionadas do comércio de serviços, nem possam ser ajustadas ao volume da população, da renda per capita e do progresso tecnológico, é possível realizar análises baseadas na informação disponível. Em primeiro lugar, os dados refletem o grau quase constantemente crescente do volume dos fluxos comerciais de bens e serviços de 1970 a 2008, e a diminuição deste volume em 2009, tanto para os países desenvolvidos como para as economias em desenvolvimento, principalmente para mercadorias. Com relação aos serviços, a tendência de crescimento tem sido bastante acentuada, particularmente nas regiões desenvolvidas, mas também nos países em desenvolvimento. Em segundo lugar, ainda é significativa a diferença no volume de comércio mercadorias em comparação com o comércio de serviços.

Em suma, a literatura econômica mostra que, durante o período analisado, os crescentes fluxos de comércio internacional foram superiores aos da produção. Há várias razões para explicar esta predominância do comércio exterior em relação aos resultados do PIB, como: cadeias globais de produção e especialização horizontal, declínio dos custos e tarifas de transportes, bem como a melhora de serviços de infraestrutura. Por outro lado, o comércio de produtos intermediários só é levado em conta no PIB por meio do valor adicionado produzido em cada etapa do processo de produção, porém, nas estatísticas do comércio de mercadorias, os bens intermediários são computados em seu valor total, cada vez que cruzam a fronteira (WTO, 2012; UNCTAD, 2010; MAURER e DEGAIN, 2010).

\subsection{A DISTRIBUIÇÃO DOS SERVIÇOS NO COMÉRCIO MUNDIAL}

O padrão de especialização da pauta de exportações e de importações de serviços é muito diferenciado entre os países, do ponto de vista geoeconômico. A composição do comércio internacional de serviços entre países desenvolvidos e em desenvolvimento, bem como entre os países dentro de cada grupo e região segundo o nível de desenvolvimento, revela a especialização econômica de cada economia. É dependente ainda das inter-relações mais intensas com países vizinhos, definindo blocos comerciais relevantes que atuam por meio de acordos de comércio, ou mesmo entre regiões distantes, por intermédio de multinacionais, como visto.

A representatividade da América Latina no contexto dos fluxos mundiais de comércio exterior de serviços é apresentada na Tabela 1, onde os dados registram a distri- 
buição geoeconômica destes fluxos de comércio, ou seja, a participação relativa de cada macrorregião selecionada no contexto mundial. No que se refere às exportações, estes países participavam em 2002, ano cujos resultados refletiram os impactos do atentado terrorista de 2001, com apenas 1\% do fluxo mundial, porém, até 2007, observou-se um crescimento gradativo desta representatividade.

Em 2008, a distribuição do crescimento do comércio mundial já mostrava um perfil amplamente desigual antes do colapso da instituição financeira Lehman Brothers nos Estados Unidos que marcou o início da recessão econômica. Em 2009, o comércio mundial de mercadorias caiu 23\%, em termos nominais em relação a 2008, o maior declínio em mais de 50 anos. Neste ano, as exportações tiveram um grande revés com redução de 12\%, enquanto o PIB mundial também diminuiu, porém, a uma taxa muito mais baixa (2,4\%). Esta queda no comércio exterior foi em razão de uma combinação de vários fatores, como a fraca demanda, os preços das commodities em queda, os impactos nas cadeias globais de suprimento, o impacto simultâneo da crise econômica entre os países e regiões, o acesso limitado ao crédito em geral e no financiamento do comércio exterior em particular (WTO, 2010b).

No entanto, a América Latina, embora também tenha apresentado reflexos negativos da crise mundial em seus fluxos de comércio exterior, no ano de 2009 mostrou aumento em sua representatividade mundial nas exportações de serviços, como consequência da queda do volume dos países mais avançados, ao contrário das importações desta região cuja participação relativa decresceu neste ano. As importações latino-americanas também não são significativas em termos de representatividade mundial, em torno de 4\% no período, todavia, são superiores aos serviços exportados.

\begin{tabular}{|c|c|c|c|c|}
\hline \multicolumn{5}{|c|}{$\begin{array}{c}\text { Tabela } 01 \text { - Distribuição regional dos fluxos de Comércio Exterior de serviços, segundo } \\
\text { regiões selecionadas, 2002, 2007, } 2009 \text { e } 2011\end{array}$} \\
\hline Países selecionados & \multicolumn{4}{|c|}{ Distribuição regional (\%) } \\
\hline Exportações & 2002 & 2007 & 2009 & 2011 \\
\hline Economias selecionadas* & 77,0 & 99,5 & 87,1 & 99,8 \\
\hline América do Norte & 15,9 & 15 & 12,2 & 17,4 \\
\hline América Latina & 1,2 & 3,2 & 3,5 & 4,4 \\
\hline Europa Ocidental & 32,6 & 46,6 & 36,6 & 40,0 \\
\hline África & 0,4 & 0,4 & 1,1 & 3,0 \\
\hline Ásia & 25,7 & 32,3 & 28,3 & 30,9 \\
\hline Europa Oriental & 1,2 & 2,0 & 5,4 & 4,1 \\
\hline \multicolumn{5}{|l|}{ Importações } \\
\hline Economias selecionadas* & 91,0 & 86,1 & 98,7 & 99,7 \\
\hline América do Norte & 21,0 & 16,3 & 17,7 & 17,0 \\
\hline América Latina & 3,8 & 3,7 & 3,0 & 4,2 \\
\hline Europa Ocidental & 38,6 & 36,7 & 39,9 & 40,5 \\
\hline África & 0,9 & 1,2 & 1,6 & 3,3 \\
\hline Ásia & 23,4 & 23,8 & 31,2 & 31,5 \\
\hline Europa Oriental & 3,2 & 4,5 & 5,3 & 3,2 \\
\hline
\end{tabular}


Quanto às importações, é importante salientar que uma grande parte do total é composta de suprimentos de insumos intermediários adquiridos por empresas para serem utilizados no processo produtivo e, muitas vezes, são reexportados como produtos acabados, e estes países menos avançados mostram maior dependência das importações para sustentar uma economia dinâmica. Nestes países, além dos serviços serem menos proeminentes, suas indústrias de serviços continuam a ser desenvolvidas pelo aproveitamento das vantagens comparativas em certos domínios específicos, como turismo, ou atendendo à crescente demanda dos países vizinhos para outros serviços de infraestrutura não tangível ou financeira.

No contexto mundial, as maiores e mais avançadas economias mundiais, incluindo os Estados Unidos, Japão e países da União Europeia, são alguns dos mais importantes fornecedores e importadores de serviços, ocupando uma posição mais elevada neste tipo de comércio em comparação com o comércio exterior de bens. Estes países respondem por uma parcela maior da economia e são mais propensos a incluir serviços no âmbito dos seus acordos de comércio exterior. Como se observa na Tabela, as economias da Europa Ocidental concentram as exportações e importações de serviços com intensidade consideravelmente superior e apresentaram um pico de participação em 2007, respectivamente de quase $47 \%$ e $37 \%$, com o movimento de queda na crise e retomada em 2011 , embora para concentração menor do que nos anos anteriores (40\%).

Como salienta relatório da WTO (2010b), esta região, juntamente com a Ásia cujos fluxos também são representativos, apresentam os maiores fluxos comerciais internamente ao próprio espaço geográfico, entre os países incluídos. No contexto europeu, no entanto, o comércio internacional da União Europeia representava mais do que $1 / 4$ do comércio mundial no período, porém, a parcela de mercado dos países desta região ou estagnou ou decresceu.

O relatório do WTO (2010) mostra que, em 2009, as exportações mundiais de Serviços Comerciais declinaram 12\% como resultado da crise global e, no ponto inferior da crise, no segundo quadrimestre daquele ano, apresentavam uma queda de quase $20 \%$ em média no ano. Estas exportações mundiais começaram a se recuperar rapidamente na segunda metade do ano, porém, a partir de um patamar muito baixo.

Ao observar-se a distribuição geoeconômica do comércio exterior de Serviços Comerciais dos países das Américas do Sul e Central, são patente as diferenças resultantes das diversas estruturas produtivas e níveis de desenvolvimento. A participação brasileira neste contexto é preponderante e crescente nas exportações, chegando a quase $30 \% \mathrm{em}$ 2011 e, entre os países que se destacam em um segundo nível na hierarquia, a Argentina contribuiu com quase $11 \%$ nesse ano, enquanto Chile e Cuba, com cerca de 9,5\%. No ano de crise de 2009, as exportações relativas do Brasil, Argentina e Chile se elevaram, embora em termos absolutos houvesse queda de $9 \%$ para os dois primeiros e de $21 \%$ para o Chile. A representatividade dos demais países nas exportações da região se distribuiu entre 1,5\% e 5,5\%. Esta taxa superior foi apresentada pelo Panamá como resultado dos serviços de transportes, portuários e de cabotagem daquele país, rota de passagem do comércio exterior de alguns países vizinhos.

Com relação à distribuição do comércio exterior entre mercadorias e serviços (Tabela 02), na maior parte dos países mundiais, as médias das exportações e das impor- 
tações de serviços mantiveram uma participação em torno de $20 \%$, do volume global (com taxas de $9 \%$ a 30\% entre as macrorregiões mundiais) em todo o período 2002-2011 (WTO, 2003 e 2012)

Tabela 02 - Distribuição entre mercadorias e serviços de países selecionados no Comércio Exterior da América Latina

\begin{tabular}{|c|c|c|c|c|c|c|}
\hline Regiões selecionadas & \multicolumn{3}{|c|}{ Mercadorias } & \multicolumn{3}{|c|}{ Serviços Comerciais } \\
\hline EXPORTAÇÕES & 2002 & 2009 & 2011 & 2002 & 2009 & 2011 \\
\hline Mundo & 80,1 & 78,5 & 80,9 & 19,9 & 21,1 & 19,5 \\
\hline América Latina & 86,4 & 78,9 & 80,5 & 13,6 & 17,9 & 8,5 \\
\hline Argentina & 90,1 & 82,1 & 91,5 & 9,9 & 16,3 & 14,3 \\
\hline Bolívia & $\ldots$ & 83,7 & 85,7 & $\ldots$ & 9,3 & 9,1 \\
\hline Brasil & 87,2 & 90,7 & 90,9 & 12,8 & 14,6 & 12,6 \\
\hline Chile & 83,6 & 85,4 & 87,4 & 16,4 & 13,5 & 12,9 \\
\hline Colômbia & 87,4 & 86,5 & 87,1 & 12,6 & 11,1 & 8,1 \\
\hline México & 92,8 & 88,9 & 91,9 & 7,2 & 6,3 & 4,1 \\
\hline Venezuela & 96,1 & 93,7 & 95,9 & 3,9 & 3,0 & 2,1 \\
\hline \multicolumn{7}{|l|}{ IMPORTAÇÕES } \\
\hline Mundo & 80,2 & 79,5 & 82,9 & 19,8 & 20,5 & 19,1 \\
\hline América Latina & 84,9 & 79,5 & 82,9 & 14,4 & 16,7 & 20,5 \\
\hline Argentina & 65,7 & 80,0 & 82,2 & 34,3 & 22,6 & 17,8 \\
\hline Bolivia & $\ldots$ & 81,6 & 28,6 & $\ldots$ & 18,4 & 71,4 \\
\hline Brasil & 77,6 & 77,4 & 76,5 & 22,4 & 24,8 & 23,5 \\
\hline Chile & 77,6 & 81,6 & 84,3 & 22,4 & 18,1 & 15,7 \\
\hline Colômbia & 78,9 & 75,2 & 85,9 & 21,1 & 17,1 & 14,1 \\
\hline México & 90,8 & 81,9 & 93,5 & 9,2 & 8,0 & 6,5 \\
\hline Venezuela & 80,4 & 82,9 & 80,0 & 19,6 & 18,5 & 20,0 \\
\hline
\end{tabular}

Fonte: WTO/World Trade Organization Report/2003 e WTO/International Trade Statistics, 2008 and 2012.

Na América Latina, apenas em 2002, a representatividade do comércio de serviços era inferior à média mundial, mas, no resto do período, não se afastou deste parâmetro. O volume destas exportações e das importações de serviços oscilou consideravelmente no período como relação do total exportado e, em 2009, sua representatividade aumenta, embora não em volume absoluto, porém, em razão da diminuição considerável dos fluxos de mercadorias de seus países, e como contrapartida à queda de participação das regiões mais desenvolvidas.

A dinâmica de evolução das compras de serviços nestes países é diferenciada da dos fluxos de vendas de serviços, ou seja, sua representatividade diminui em 2007, embora não muito consideravelmente, e aumenta no ano de 2009. Dessa forma, no decorrer da crise, as importações mais elevadas de insumos na forma de produtos de serviços estiveram relacionados à busca de soluções para a ultrapassagem das difi- 
culdades do crescimento da economia, de modo diferenciado por meio de categorias específicas de serviços burocráticos e financeiros.

Entre os países selecionados latino-americanos, observa-se em 2002 que a Argentina se destacava como maior importadora de serviços em relação às demais, porém, se iguala no período posterior; por sua vez, a Venezuela e o México apresentam respectivamente em torno de $95 \%$ acima de $90 \%$ de suas exportações em mercadorias. Este último país mostra a menor participação em importações de serviços, no período.

A Organização Mundial do Comércio nota que não há relação direta entre o grau de representatividade das importações de um país de serviços e seu nível de desenvolvimento, mas há uma relação com o ambiente mais ou menos dinâmico da economia em cada período (WTO, 2010a). No entanto, é necessário verificar que, no que se refere à interdependência entre as mercadorias e os serviços no comércio internacional, a mensuração não foi possibilitada somente com base nos dados do comércio internacional, porque os serviços são parte integrante do processo de produção de bens, no que diz respeito à integração econômica e setorial, como já mencionado, e os dados de mercadorias não mostram a participação das atividades de serviços interiormente aos processos de produção de mercadorias. Portanto, embora de difícil mensuração, as alterações ao longo do tempo no conteúdo de serviços inserido na produção de bens, ou seja, o fato de que as mercadorias estão evoluindo para serem intensivas em serviços, também devem ser levadas em consideração na avaliação da contribuição dos serviços para a interdependência global no comércio internacional.

\subsection{A EVOLUÇÃO DO COMÉRCIO INTERNACIONAL DE SERVIÇOS: AMÉRICA LATINA NO MUNDO}

Dados da OMC sobre as taxas de crescimento anuais dos fluxos de comércio internacional, desde a segunda metade da década de 1990, mostram que os anos até 1995 foram marcados por um crescimento muito intenso no comércio mundial de serviços, tanto nos países desenvolvidos da América do Norte, Europa e Ásia, como nos países emergentes da América Latina. Porém, as citadas crises de 1997 tiveram impactos negativos consideráveis sobre o comércio exterior mundial de serviços em 1998 e 1999 $(-14,1 \%)$ e, em 2001, um grande número de países desenvolvidos (exceto os da Europa Ocidental), bem como da América Latina sofreram impactos da desaceleração da economia mundial, mostrando taxas de crescimento negativas ou baixas para estas operações internacionais (WTO, 2003 e 2008).

Além dos maiores impactos negativos dos ataques terroristas de 11 de setembro de 2001 nos Estados Unidos com relação às exportações, as taxas consideravelmente negativas da América Latina nas importações destes fluxos, em 2002 e 2003, também decorreram de problemas conjunturais macroeconômicos de países representativos como a Argentina e o Brasil. No entanto, neste último ano, a recuperação das regiões da Europa Ocidental (em torno de 9\%) e da Ásia, que já havia se iniciado em 2002, elevando a média de crescimento do valor do comércio internacional de serviços para mais de 5\%, repercutiu de maneira significativa também entre estes países latino-americanos, tanto para exportações quanto para importações. 
A recuperação depois deste período se verificou, em todas as regiões mundiais a partir de 2004, a taxas elevadas tanto para as vendas como para as compras de serviços do exterior, com maior intensidade na América Latina, em relação à media mundial. As altas taxas continuaram até 2008, pois, no ano seguinte, já refletiam as repercussões negativas da crise financeira internacional sobre o crescimento do comércio exterior que, na média mundial, resultaram em quedas de $12 \%$ nas exportações e importações, que foram ultrapassadas nos dois anos seguintes, pois, em 2011, os fluxos de exportação e importação mundiais registraram crescimento de 11\%.

No ano de 2009, em todas as macrorregiões mundiais, as taxas de crescimento dos fluxos de exportações e importações dos Serviços Comerciais tiveram quedas consideráveis que, no entanto, se reverteram rapidamente nos dois anos seguintes, como mostra a Figura 1 como consequência do baixo patamar dos fluxos do ano anterior. Estas taxas foram mais expressivas, particularmente na América Latina, retomando em 2011 ao patamar médio de crescimento anterior à crise. Considerando-se os fluxos de crescimento das exportações do período 2005-2011, é observado que os países desenvolvidos das regiões da América do Norte e da Europa Ocidental apresentaram taxas de crescimento inferiores à média mundial, enquanto que os países da América do Sul e Central ultrapassaram esta média. Por sua vez, os fluxos de importações tiveram um desempenho muito semelhante mostrando um crescimento mundial médio anual no período $2005-2011$ de 9\% e os desempenhos mais diferenciados positivos se verificaram nas Américas do Sul e Central (67\% acima da média mundial), onde o aumento das importações foi muito relevante em 2008 (21\%), em virtude principalmente à considerável desvalorização do dólar, que estimulou a modernização nas empresas, por meio de importações de Serviços Comerciais.

O exame mais detalhados dos fluxos comerciais de países selecionados da América do Sul e Central mostra primeiramente o crescimento gradativo das vendas e compras de serviços ao exterior e a maior taxa de evolução média de crescimento se deu no período de 2005-2011, não obstante a queda considerável do ano de 2009. Por outro lado, observa-se a considerável disparidade nos volumes de exportações do Brasil em relação aos demais, no que se refere à participação relativa no global das vendas e compras de serviços, bem como da evolução desta concentração no período. No que se refere às taxas de evolução das vendas de serviços ao exterior nos anos selecionados do período (exceto em 2009), destacam-se além deste país, a Argentina, Chile, Uruguai, Panamá, Colômbia, com evolução considerável acima de 20\% em cada ano, seguidos de Costa Rica e Peru, cujo crescimento foi significativo em todo os anos, mas também Cuba no ano de 2011, (especialmente com exportações de serviços de saúde). As importações de serviços mostram taxas de evolução significativas em quase todos os anos analisados no Brasil, Argentina, Chile, Venezuela, Colômbia, Peru, o que significa um maior movimento em direção à modernização dos processos produtivos, pela introdução de serviços mais avançados não produzidos no próprio país.

\subsection{CRESCIMENTO E DISTRIBUIÇÃO DO COMÉRCIO EXTERIOR, SEGUNDO AS CATEGORIAS DE SERVIÇOS COMERCIAIS}

As modalidades significativamente diferenciadas de Serviços Comerciais foram agrupadas de três categorias específicas pela OMC para fins de facilitar a mensuração 
dos fluxos, tendo em vista a natureza comum de algumas das características que foram incluídas nos respectivos grupos de Transportes, Viagens e Outros (WTO, 2004). Foram incluídos na categoria de Transportes os serviços de transporte aéreos, terrestres, marítimos e os serviços auxiliares a todas as modalidades de transportes, que incluem serviços de operacionalização de cargas, armazenamento e depósito, agências de fretamento, e outros auxiliares voltados para informações sobre tarifas e serviços burocráticos na área, inspeção, embarque e desembarque e outros.

Os serviços que compõem a categoria Viagens, ao contrário das outras categorias, não são considerados um tipo específico de serviços em si, mas sim são estatisticamente mensurados mediante a comercialização de bens e serviços adquiridos por viajantes (pessoais e comerciais), mais comumente representados por passagens, alojamento, alimentação, entretenimento, transportes na economia visitada, presentes e souvenirs. Os denominados Outros Serviços Comerciais agregam os serviços de Comunicação, Construção, Seguros, Financeiros, de Computação e Informática, Royalties e Tarifas de licenças - que cobrem pagamentos e receitas pelo uso de ativos intangíveis não financeiros e direitos de propriedade (como patentes, direitos autorais ou copyrights, marcas registradas, processos industriais e franquias) - , Outros Serviços Empresariais relacionados ao comércio internacional, como de aluguéis (leasing), serviços técnicos e profissionais de contabilidade, administração, consultoria, relações públicas, publicidade, pesquisa de mercado, outros serviços de pesquisas e planejamento, arquitetura, engenharia e outros técnicos. Finalmente, também se incluem nestas categorias os Serviços Pessoais, Culturais, Recreativos e Audiovisuais.

Como se observa na Figura 01, que registra o período anterior à crise financeira mundial de 2008, mostrando as taxas de evolução anuais dos fluxos para o período de 2000 a 2007, os países do grupo de economias em transição (CEI) tiveram uma elevação dos fluxos de comércio exterior consideravelmente superior aos demais e, embora participassem com apenas $2,5 \%$ do comércio mundial, esta participação aumentou $75 \%$, e as taxas de crescimento anuais das diversas modalidades de serviços foram consideráveis: respectivamente de 16\%, 20\% e 28\% para as categorias de Transportes, Viagens e Outros Serviços. Isto aconteceu por causa dos fluxos comerciais da Rússia e da Ucrânia, e ainda das importações do Kazakistão, que se tornou no período o segundo maior importador de Serviços Comerciais, depois da Rússia (WTO, 2008). 


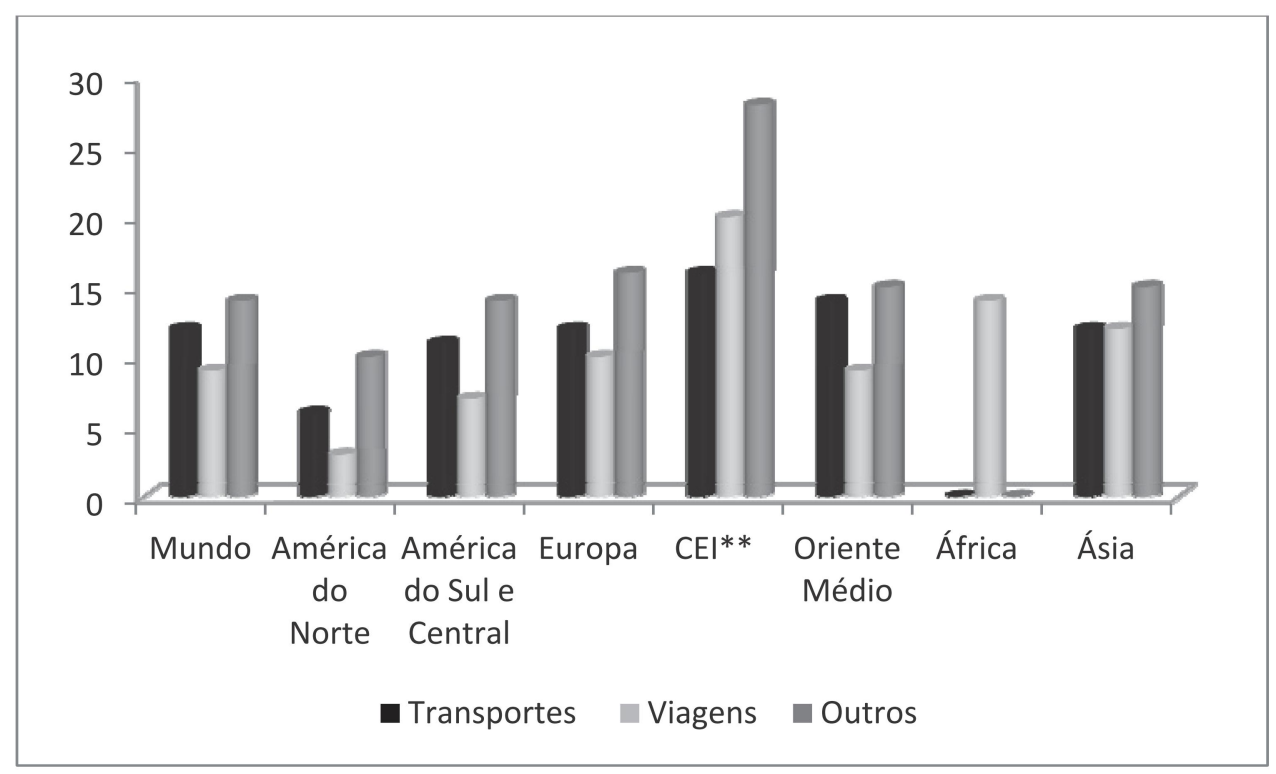

\section{GRÁFICO 01}

CRescimento ANUAL REGIONAL DO COMÉRCIO INTERNACIONAL DE SERVIÇOS POR CATEGORIAS: 2002-2007

Fonte: WTO/International Trade Statistics, 2001 e 2008. Elaboração própria.

Em termos relativos, no período de 2000 a 2007, o crescimento anual dos fluxos de comércio exterior de serviços das Américas do Sul e Central e do Norte foram menores que a elevação da média mundial para as categorias de Transportes e Viagens, porém, superaram esta média para os denominados Outros Serviços Comerciais. Na América do Sul e Central, estes resultados ainda refletiam as dificuldades anteriores com a dívida externa destes países desde a década de 1980. Apesar de que, na década de 1990, o desempenho das exportações e importações da América do Sul foi de expansão muito mais intensa que a média mundial, no período seguinte verificou-se uma diminuição da intensidade, tendo em vista que os fluxos líquidos de entrada de capital para estas regiões - que apoiavam os investimentos e as importações e consequentemente a atividade econômica - diminuíram consideravelmente desde 2001. Os fluxos diminuiram novamente no ano seguinte, quando as importações de serviços comerciais da América Latina decresceram em mais de $10 \%$ e as exportações em torno de $5 \%$, impactando o comércio exterior como um todo e mais especificamente o de serviços (WTO, 2003).

Assim, no ano de 2007, em que se iniciou a intensificação das questões que levaram à crise financeira mundial, o valor do comércio internacional em Serviços Comerciais aumentou a uma taxa superior (18\%) à de bens (15\%), pela primeira vez, em cinco anos. Isto se verificou pela expansão internacional da oferta de muitos novos serviços e ao aumento dos preços dos transportes. Enquanto o setor de serviços gerou aproximadamente $2 / 3$ do valor adicionado total mundial, sua parte no comércio internacional ainda permanecia abaixo de 19\%. O impacto da crise nos setores bancário e financeiro e 
as consequentes medidas de protecionismo das empresas norte-americanas ao limitar a compra externa de serviços, tiveram um resultado negativo importante nas exportações em 2009, em quase todas as regiões mundiais que mostraram taxas de decréscimo consideráveis neste ano (WTO, 2010).

A figura 02 demonstra que, em 2008, as taxas de crescimento dos fluxos de serviços da América Latina eram superiores à media mundial, porém, no período de 2009, os impactos negativos foram consideráveis sobretudo os serviços de Transportes foram os que sofreram os maiores impactos negativos para as exportações, quando as taxas negativas se situaram respectivamente em $18 \%$ e $23 \%$ para a região e a média mundial, e com queda ainda mais expressivas para as importações, com $24 \%$ e $22 \%$.

Isto se verificou particularmente em razão da forte retração das transações de mercadorias a serem transportadas e do fluxo de turismo, contudo, a recuperação mostrada já no ano de 2011 também foi intensa nas três categorias não apenas nesta região, mas igualmente em outras regiões do mundo, com exceção da Europa e da Ásia, em que as Viagens e Outros Serviços Comerciais ainda refletiam a crise financeira com maior intensidade.

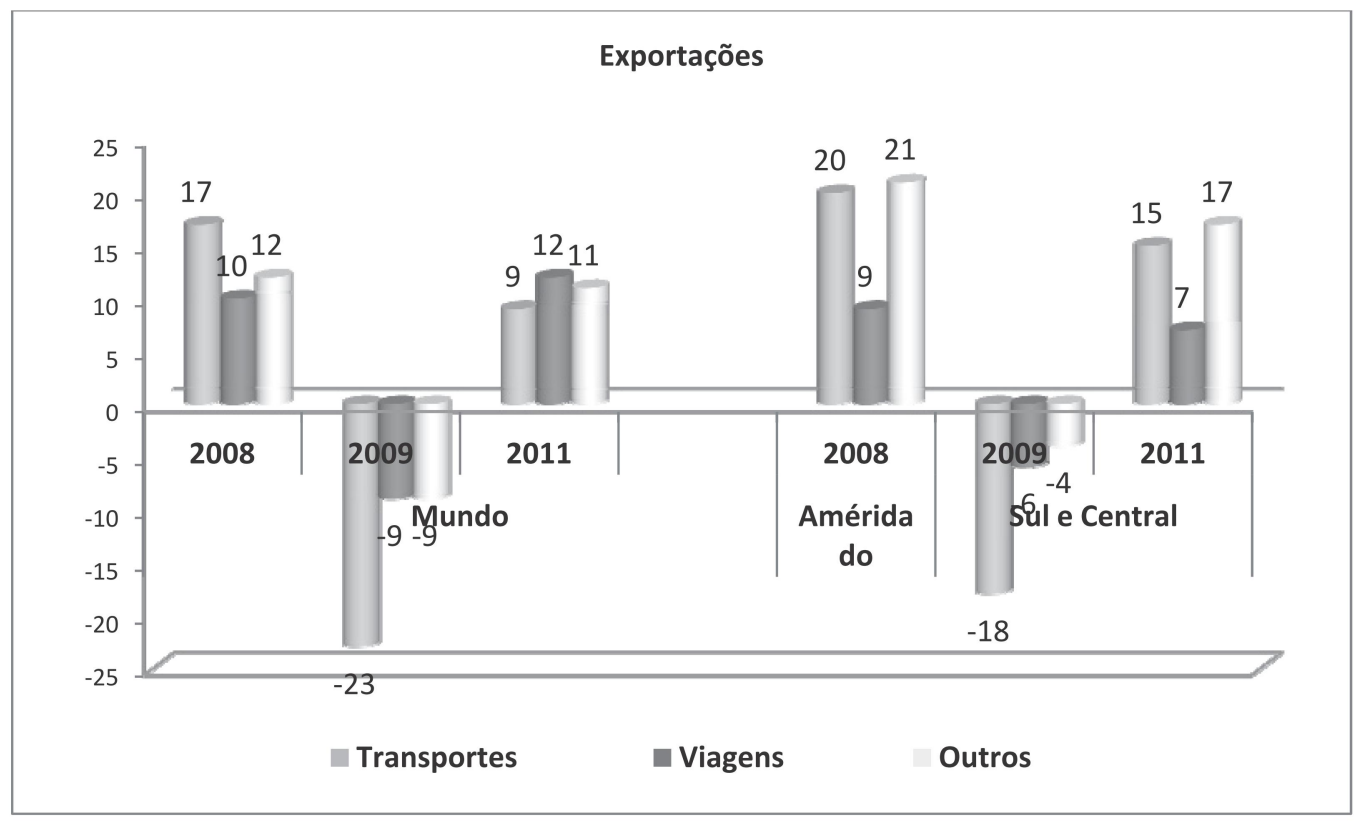

\section{GRÁFICO 02}

Crescimento anual do COMÉRCIO INTERNACIONAL DE SERVIÇOS POR CATEGORIAS na América Central e do Sul, 2008, 2009 e 2011

Fonte: WTO/International Trade Statistics, 2009 e 2012. Elaboração própria.

\section{CONSIDERAÇÕES FINAIS}

Em resumo, os rápidos avanços tecnológicos que ocorreram nas últimas décadas do século XX nas áreas de computação, transportes e telecomunicações, incluindo o 44 
desenvolvimento da Internet e e-commerce, levaram as empresas à busca de suprimentos disponíveis em espaços mais distantes, para servirem como insumos que lhes permitiria também atender aos mercados mais amplos. Esta tendência em direção à globalização foi reforçada por políticas de liberalização associadas à desregulação de atividades econômicas, que promoveu o crescimento de investimentos diretos internacionais em comércio exterior de bens e serviços.

Existem claras evidências de que a América Latina vem aumentando seus fluxos mundiais de serviços, inclusive no que se refere às exportações, mas persistem divergências significativas na distribuição mundial destas atividades de comércio internacional, pois a evolução destes fluxos em períodos de bonança internacional não eliminou as desvantagens destes países e nos períodos de crise os impactos também foram contundentes nesta região, embora em menor grau, porém, este crescimento relativo em períodos de crise resulta da perda de representatividade de alguns países desenvolvidos no comércio mundial em períodos de crise.

Diferenças nas dotações de recursos naturais e capacidade de força de trabalho podem explicar as diversas influências no desempenho das exportações. Como salientado pela OCDE e pelas análises da OMC, eventos conjunturais colaboraram para as diversidades internas da América Latina e de sua posição diante da média mundial, como os vários graus de investimento direto estrangeiro em diferentes períodos e outros fatores restritivos que afetaram a presença comercial, como as relativas ao licenciamento, às parcerias conjuntas de risco e ao movimento permanente de pessoas. Outras restrições ainda se referem à ascensão e a empréstimos de fundos, a restrições legais e culturais ao fornecimento de outros negócios (seguros e valores imobiliários), a impossibilidades de expansão da circulação temporária de pessoas em período de crises, paralelamente, às flutuações cambiais e às incertezas quanto à soberania econômica dos países endogeneizaram os riscos externos das economias.

Na realidade, a diminuição da disparidade desfavorável à América Latina, nos fluxos de comércio internacional de serviços, exige um compromisso governamental com a abertura comercial externa e com políticas internas voltadas para estes objetivos. Assim, nestes países, isto significa a implementação de políticas governamentais que geram a estabilidade macroeconômica, mas também mercados de trabalho flexíveis, a boa governança e políticas ambientais eficazes. Com certeza, os custos de ajustamento podem desempenhar papel significativo na formação da economia política das reformas comerciais. Os benefícios da abertura não serão uniformemente compartilhados entre as economias, pois alguns países vão ganhar e outros perder e, além disso, os resultados podem levar duração de tempo diferentes para surgirem.

\section{BIBLIOGRAFIA}

BAUMOL, William. Productivity Policy and the Service Sector. Work Paper, n. 01, Fishman-Davidson Center for the Study of the Service Sector, Washington DC, 1987.

BRYSON, Alex; WHITE, Michael. Moving in and out of self-employment. London: Policy Studies Institute, 1997. 
DANTAS, Fernando. Crise da indústria se agrava e assusta. In: Estado de São Paulo: 11 de março de 2012.

HAUKNES, Johan. Innovation in the Service Economy. Norway: STEP Goups, 1996.

KON, Anita. Economia de Serviços. Rio de Janeiro: Elsevier/Campus, 2004.

. Estrutura e dinâmica da economia de serviços: transformações sistêmicas e desafios ao desenvolvimento no Brasil. Relatório de Pesquisa CNPQ, Brasília, 2012.

MAURER, Andreas; DEGAIN, Christophe. A globalização mundial da Organização do Comércio e os fluxos de comércio: o que você vê não é o que você ganha. Documento de trabalho ERSD-2010-12, Geneve, 2010.

REINHARDT, Uwe. Is There Hope for the Unemployed? New York: Economix, 2011.

UNCTAD. Trade and Development Report, UM, Genebra, 2010.

WORLD BANK. World Development Report 2007, Genebra, 2008.

WTO. Final Act of the 1986-1994 Uruguay Round of Trade Negotiation, Marrakesh, 2004.

The General Agreement on Trade in Services (GATS): objectives, coverage and disciplines.

Geneva, 1995.

. World Trade Developments, Genebra, 2008.

World Trade Organization Report, Washington, 2003, 2009, 2010 e 2012. 